\title{
Cisplatin plus Gemcitabine in patients with inoperable or metastatic pancreatic cancer
}

\author{
Hanan Selim, Mohamed Abdalla, Amr Sakr, Tamer EL Nahas \\ All authors from Kasr Al-Aini Center of Radiation Oncology and Nuclear Medicine (NEMROCK), Faculty of \\ Medicine, Cairo University, Egypt.
}

\begin{abstract}
:
Aim of the work: The objectives of this study were to evaluate the efficacy and toxicity of combination chemotherapy with cisplatin and gemcitabine in patients with inoperable or metastatic pancreatic cancer.

Patients and Methods: the study included patients with histologically or cytologically confirmed inoperable or metastatic pancreatic adenocarcinoma. Gemcitabine was given by IVI at a dose of $1000 \mathrm{mg} / \mathrm{m}^{2}$ over $30 \mathrm{~min}$ on days 1 and 8 and cisplatin was given by IVI at a dose of $80 \mathrm{mg} / \mathrm{m}^{2}$ over $150 \mathrm{~min}$ on day 1 , of a 3-week cycle.

Results: Twenty-five patients with previously untreated, unresectable or metastatic pancreatic cancer were enrolled in this study between August 2003 and December 2005 at the Kasr Al-Aini Center of Radiation Oncology and Nuclear Medicine (NEMROCK), Faculty of Medicine, Cairo University. The median age was 52 years; (range 36 -68). There were no complete responses. Five (20\%) patients had partial responses, 16(64\%) patients and $4(16 \%)$ patients had Stable and progressive disease, respectively. The median overall survival was 7.1 months; the median TTP was 4.6 months and 1-year survival was 20\%. The Clinical benefit response was observed after the second cycle of chemotherapy, 8 of 19 patients (42\%) experienced decreased pain intensity and reduced the daily dose of analgesics. At the same time, (33.3\%) and (23.8\%) patients experienced gain their weight and improvement in Kranofsky $P S$, respectively.

The most common toxicities were myelosuppression, especially neutropenia and thrombocytopenia. Grade 3-4 neutropenia and thrombocytopenia occurred in 52 and $48 \%$ of the patients, respectively.

Conclusion: The combination of cisplatin and gemcitabine produced a good response rate associated with moderate but manageable toxicities in patients with inoperable or metastatic pancreatic cancer.
\end{abstract}

Key words: cisplatin, gemcitabine, pancreatic cancer

\section{Introduction:}

The overall survival rate of patients with pancreatic cancer is extremely disappointing (1), since most of the patients present with unresectable, locally advanced or metastatic disease. The prognosis is dismal with only $1 \%$ to $4 \%$ surviving at 5 years (2).

Gemcitabine is the only approved therapy for inoperable pancreatic cancer (3). In several phase III studies, single agent gemcitabine showed response rates from 5.4\% to $26 \%$, with median survival of about 6 months and 1-year survival of $20 \%(4-8)$. These results were significantly better compared with the previous standard of care 5-fluorouracil, moreover, a considerable improvement was observed beyond that suggested by objective response rates. As a result, the term clinical benefit response was introduced as a primary endpoint to evaluate the efficacy of gemcitabine, and the drug is considered as the reference treatment for advanced pancreatic cancer (9). The need exists to further improve the prognosis of patients with inoperable pancreatic cancer. Numerous randomized studies have compared gemcitabine monotherapy with gemcitabine-based cytotoxic combination regimens (10). While some of these trials have shown benefits for the end points of progression-free survival or response rates, yet an improvement in overall survival over that achieved with gemcitabine alone has been demonstrated since 2005 (11-14).

This study was conducted to determine whether the combination of gemcitabine and platinum would improve the overall survival and response rates in patients with unresectable or metastatic pancreatic cancer.

\subsection{Patient selection:}

\section{Patients and Methods:}

Patients were eligible for this study if they had histologically or cytologically proven pancreatic adenocarcinoma that was either unresectable or metastatic. Other eligibility criteria included: no previous treatment for pancreatic cancer except surgery; age $\geq 20$ and $\leq 74$ years, with at least one bidimensionally measurable lesion with clearly defined margins by computed tomography (CT) or magnetic resonance imaging (MRI), Karnofsky performance status (KPS) $\geq 50$, adequate bone marrow function (white blood cell count $\geq 4000 / \mathrm{mm}^{3}$, neutrophil count $\geq 2000 / \mathrm{mm}^{3}$, platelet count $\geq 100000 / \mathrm{mm}^{3}$ and hemoglobin level $\geq 10.0 \mathrm{~g} / \mathrm{dl}$ ), adequate renal function (serum creatinine concentration $\leq$ upper limit of normal and creatinine clearance $\geq 60$ 
$\mathrm{ml} / \mathrm{min}$ ), adequate hepatic function (serum bilirubin level $\leq 2.0 \mathrm{mg} / \mathrm{ml}$, serum aspartate and alanine transaminase (AST and ALT) levels $\leq 2.5$ times upper normal limit or $\leq 5$ times upper normal limit if liver metastases or biliary drainage were present). Exclusion criteria included: symptomatic pulmonary fibrosis or interstitial pneumonia, marked pleural effusion or ascites, central nervous system metastasis, active concomitant malignancy, severe mental disorder, serious complications such as active infection, active gastrointestinal ulcer, or cardiac disease and pregnant or lactating women.

\subsection{Treatment plan:}

The patients received gemcitabine at dose of $1000 \mathrm{mg} / \mathrm{m}^{2}$ intravenously (IV) over $30 \mathrm{~min}$ on days 1 and 8 , and cisplatin at dose of $80 \mathrm{mg} / \mathrm{m}^{2}$ just after gemcitabine over 2 hours on day 1 as IV infusion after IV prehydration with 1 liter of $0.9 \%$ sodium chloride containing $20 \mathrm{mmol}$ potassium chloride and 1gram of magnesium sulphate. After cisplatin administered, at least 2 liter of saline as post-hydration to maintain a urine output of $100 \mathrm{ml} / \mathrm{h}$ during and for $6-8$ hours after cisplatin administration.

The treatment cycles were repeated every 3 weeks for a maximum of six cycles unless disease progression or unacceptable toxicity occurred. Standard antiemetic treatment with ondansetron was given to all patients only on the day of administration of chemotherapy. Dose reduction of gemcitabine from $1000 \mathrm{mg} / \mathrm{m}^{2}$ to $800 \mathrm{mg} / \mathrm{m}^{2}$ was allowed when patients experiend grade 4 leukopenia or neutropenia, grade 3 thrombocytopenia requiring blood transfusion, febrile neutropenia, or grade 3 or 4 non-hematological toxicities other than nausea, vomiting, anorexia and hyperglycemia.

\subsection{Patient evaluation}

Prior to treatment, each patient was evaluated by medical history, physical examination, full blood cell count, blood chemistry, tumor markers (CEA and CA 19.9) and urine analysis. Computed tomography (CT) scans of chest and abdomen were also performed.

Karnofsky performance status, weight, disease-related symptoms and especially pain, as well as analgesic consumption, were evaluated at base line and at the completion of second, fourth and sixth cycle of chemotherapy thereafter.

During chemotherapy, full blood counts with differential and biochemical test were performed before each cycle of chemotherapy. CT scan or MRI was done every 3 cycles of chemotherapy to assess objective response. Patients underwent follow-up examination every 2 months. Tumor response was evaluated using the criteria of the world health organization (WHO) (15). Toxicities were graded according to the National Cancer Institute common toxicity criteria version $2.0(16)$.

\subsection{Study end points:}

The primary end points were the assessment of response rate and clinical benefit. Secondary end points included survival, time to progression and toxicity.

Clinical benefit response is composite assessment of clinical parameters including pain, PS and weight loss, and was evaluated according to previously established criteria (3). The assessment of pain relief was based on both the consumption of analgesics and the patient own evaluation of pain using an optical scale graded from 0 (no pain) to 10 (maximum pain necessitating analgesics for relief (3).

Pain improvement was characterized by a $>50 \%$ reduction in analgesic consumption coupled with the patient own evaluation of $>50 \%$ decrease in pain intensity. Pain deterioration was defined as any increase of initial pain intensity by $>50 \%$ of the patients own evaluation prior to treatment, coupled with increased or at least stable analgesic consumption.

Improvement in PS was denoted as $\geq 20$ points from above baseline, and weight gain $\geq 7 \%$ from baseline sustained for $\geq 4$ weeks (3).

For patients to achieve an overall rating of positive clinical benefit response, they had to be positive for at least one parameter (pain, performance status, or weight) without being negative for any of the others. This improvement had to last for at least 4 weeks.

Time to tumor progression (TTP) was calculated from the date of the start of therapy until documented disease progression or death owing to any cause, whichever occurred first. For patients still alive at the time of analysis and who did not have disease progression, TTP was censored at the date of the last follow-up visit. Overall survival was calculated from the date of the start of therapy to the date of death owing to any cause. Patients alive on the date of the last follow-up visit were censored on that date. Median survival and the median TTP were estimated by the Kaplan-Meier method. 


\subsection{Patient's characteristics}

\section{Results:}

Twenty-five patients (19 male, 6 female) with unresectable or metastatic pancreatic cancer were enrolled in this study between August 2003 and December 2005. The patient characteristics are shown in Table 1.The Median age was 52 years; (range 36-68). Before the start of the treatment, the majority of patients $(84 \%)$ had stage IV disease and $15(60 \%)$ patients had liver metastases. Four $(16 \%)$ patients had undergone surgical resection and seven $(28 \%)$ patients had undergone biliary drainage for obstructive jaundice. Abdominal and/or back pain was the most common initial symptoms among $19(76 \%)$ patients, followed by weight loss $(60 \%)$, and anorexia (40\%) before treatment. The karnoksky PS was as follows: $80-70 \%$ in $3(12 \%)$ patients, $70-60 \%$ in $7(28 \%)$ patients, and $60-50 \%$ in $15(60 \%)$ patients.

\subsection{Treatments}

A total of 96 cycles were administered to the 25 patients with a median of 3 cycles per patient (range $2-6)$. Gemcitabine was administered on day 8 in $83(86 \%)$ of the 96 cycles. Gemcitabine dose reduction was required in $4(16 \%)$ patients owing to grade $3-4$ hematological toxicity, and in $2(8 \%)$ patients due to elevated hepatic enzymes (grade 3 ).

\subsection{Response to treatment and survival}

There were no complete responses observed. Five patients (20\%) achieved partial responses (PR), Stable disease (SD) was observed in 16 patients (64\%). Progressive disease (PD) was observed in four patients $(16 \%)$, two of them after the third cycle of treatment accompanied with increase pain intensity and deterioration of performance status. table(2).

At the time of analysis, all the patients were confirmed to be dead. The cause of death was disease progression in all cases. With a median follow up of 4 months, (range 3-12). The median TTP was 4.6 months and the median overall survival was 7.1 months with a 1 -year survival rate of $20 \%$ (Fig. 1 \& 2).

\subsection{Clinical Benefit response}

Clinical benefit response data are summarized in table 2.

Nineteen $(76 \%)$ patients had severe pain prior to treatment. All patients consumed analgesic in the form of either NSAIDs (14 patients) or tramadol HCL (5 patients) prior to treatment. After the second cycle of chemotherapy 8 of 19 patients $(42 \%)$ experienced pain intensity improvement $>50 \%$ and reduced the daily dose of analgesic by $>50 \%$. Six (31.5\%) patients remained stable and $5(26.3 \%)$ patients worsened. All patients had Karnofsky PS $80 \%$ or less before the treatment. Improved Karnofsky PS by $>20 \%$ points from baseline was observed in five of 21 patients $(23.8 \%)$ after the second cycle of chemotherapy, whereas $13(61.9 \%)$ patients remained stable and $3(14.2 \%)$ worsened. After the end of six cycle of chemotherapy, $13(68.4 \%)$ patients out of 19 showed improved Karnofsky PS. Fifteen (60\%) patients had significant weight loss before treatment. After the second cycle of chemotherapy 5 out of 15 patients $(33.3 \%)$ experienced a weight gain of at least $7 \%$, this percent was elevated up to $76.9 \%$ (10 out 13 patients) at the end of treatment. The median time to achieve a clinical benefit response was 6 weeks.

\subsection{Toxicity}

All 25 patients were evaluated for toxicities during treatment, which are listed in Table (2). The most common toxicities were myelosuppression, especially neutropenia and thrombocytopenia. Grade 3-4 neutropenia and thrombocytopenia occurred in 52 and $48 \%$ of the patients, respectively. Most of these hematologic toxicities were transient and reversible. Three patients required hospitalization as a result of grade 4 neutropenia and fever. No other unexpected severe toxicities were observed during the study and there were no treatment-related deaths. Although gastrointestinal toxicities such as nausea, vomiting and anorexia were frequently observed after cisplatin administration, most of them were manageable with appropriate medical treatment. 
Table (1): Patient's characteristics $(n=25)$

\begin{tabular}{|c|c|c|}
\hline Characteristics & No. of patients & $(\%)$ \\
\hline $\begin{array}{l}\text { Gender } \\
\text { Male } \\
\text { Femal }\end{array}$ & $\begin{array}{c}19 \\
6\end{array}$ & $\begin{array}{l}(76) \\
(24)\end{array}$ \\
\hline $\begin{array}{l}\text { Median age } \\
\text { [range] }\end{array}$ & $\begin{array}{c}52 \text { years } \\
(36-68)\end{array}$ & \\
\hline $\begin{array}{l}\text { KPS } \\
80-70 \% \\
70-60 \% \\
60-50 \%\end{array}$ & $\begin{array}{c}3 \\
7 \\
15\end{array}$ & $\begin{array}{l}(12) \\
(28) \\
(60)\end{array}$ \\
\hline $\begin{array}{l}\text { Initial symptoms: } \\
\text { Pain } \\
\text { Weight loss. } \\
\text { Anorexia } \\
\end{array}$ & $\begin{array}{l}19 \\
15 \\
10 \\
\end{array}$ & $\begin{array}{l}(76) \\
(60) \\
(40)\end{array}$ \\
\hline History of surgical resection & 4 & (16) \\
\hline History of biliary drainage & 7 & (28) \\
\hline $\begin{array}{l}\text { Sites of metastases } \\
\text { Liver } \\
\text { Lung } \\
\text { Lymph node } \\
\text { peritoneum }\end{array}$ & $\begin{array}{c}15 \\
6 \\
7 \\
3\end{array}$ & $\begin{array}{l}(60) \\
(24) \\
(28) \\
(12)\end{array}$ \\
\hline
\end{tabular}

Table (2): treatment results of 25 patients with local advanced and metastatic pancreatic cancer treated with gemcitabine and cisplatin.

\begin{tabular}{|c|cc|}
\hline Treatment response & No. of patients (\%) \\
\hline Complete Response (CR) & 0 \\
\hline Partial Response (PR) & 5 & $(20)$ \\
\hline Stable Disease (SD) & 16 \\
\hline Progressive disease & 4 \\
\hline $\begin{array}{l}\text { Survival (months): } \\
\text { Median }\end{array}$ \\
Range & 7.1 \\
\hline $\begin{array}{l}\text { TTP (months) } \\
\text { Median } \\
\text { Range }\end{array}$ & $\begin{array}{l}(3-14) \\
\text { Follow-up (months) } \\
\text { Median }\end{array}$ & $(2-14)$ \\
Range & 4 \\
\hline
\end{tabular}

Table (3): Results of clinical benefit response.

\begin{tabular}{|c|c|c|c|c|c|c|}
\hline \multirow[t]{2}{*}{ variable } & \multicolumn{2}{|c|}{ After $2^{\text {nd }}$ cycle } & \multicolumn{2}{|c|}{ After 4th cycle } & \multicolumn{2}{|c|}{ After 6th cycle } \\
\hline & NO & $(\%)$ & NO & $(\%)$ & NO & (\%) \\
\hline \multicolumn{7}{|l|}{ Pain: } \\
\hline Improvement & $8 / 19$ & $(42.1)$ & $10 / 17$ & $(58.8)$ & $10 / 17$ & $(58.8)$ \\
\hline Stable & $6 / 19$ & (31.6) & $5 / 17$ & $(29.4)$ & $5 / 17$ & (29.4) \\
\hline worsening & $5 / 19$ & $(26.3)$ & $2 / 17$ & $(11.8)$ & $2 / 17$ & $(11.8)$ \\
\hline \multicolumn{7}{|c|}{ Analgesic consumption : } \\
\hline Improvement & $8 / 19$ & $(42.1)$ & $11 / 17$ & $(64.7)$ & $13 / 17$ & $(76.5)$ \\
\hline Stable & $6 / 19$ & $(31.6)$ & $4 / 17$ & $(23.5)$ & $2 / 17$ & $(11.8)$ \\
\hline worsening & $5 / 19$ & $(26.3)$ & $2 / 17$ & $(11.8)$ & $2 / 17$ & $(11.8)$ \\
\hline \multicolumn{7}{|l|}{ Karnofsky PS: } \\
\hline Improvement & $5 / 21$ & $(23.8)$ & $8 / 19$ & $(42.1)$ & $13 / 19$ & $(68.4)$ \\
\hline Stable & $13 / 21$ & $(61.9)$ & $10 / 19$ & $(52.6)$ & $5 / 19$ & $(26.3)$ \\
\hline worsening & $3 / 21$ & $(14.2)$ & $1 / 19$ & $(5.2)$ & $1 / 19$ & $(5.3)$ \\
\hline \multicolumn{7}{|l|}{ Weight : } \\
\hline Improvement & $5 / 15$ & (33.3) & $6 / 13$ & $(46.2)$ & $10 / 13$ & (76.9) \\
\hline Stable & $8 / 15$ & $(53.3)$ & $7 / 13$ & $(53.8)$ & $3 / 13$ & (23.1) \\
\hline worsening & $2 / 15$ & $(9.5)$ & 0 & 0 & 0 & 0 \\
\hline
\end{tabular}


Figure (1): progression free survival curve.

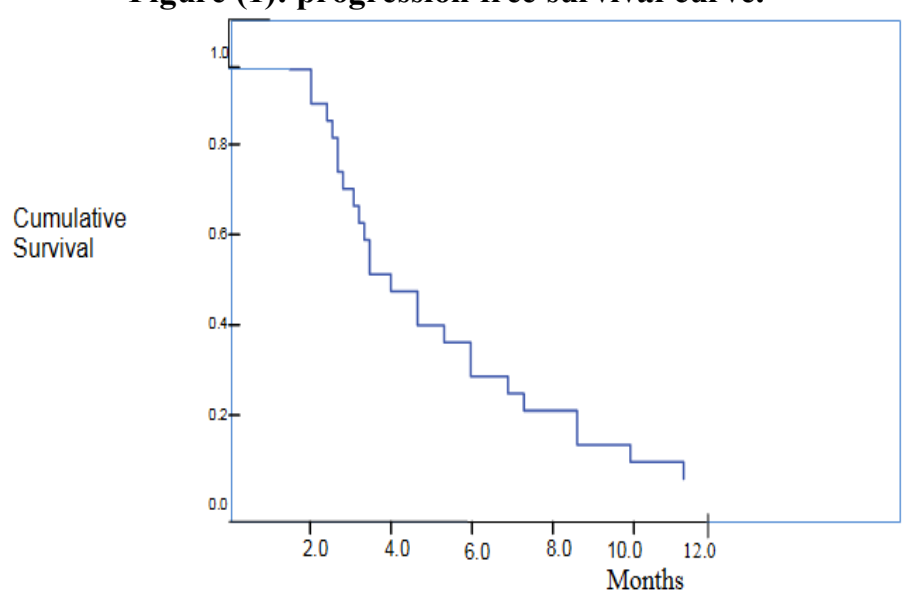

Figure (2): Overall survival curve

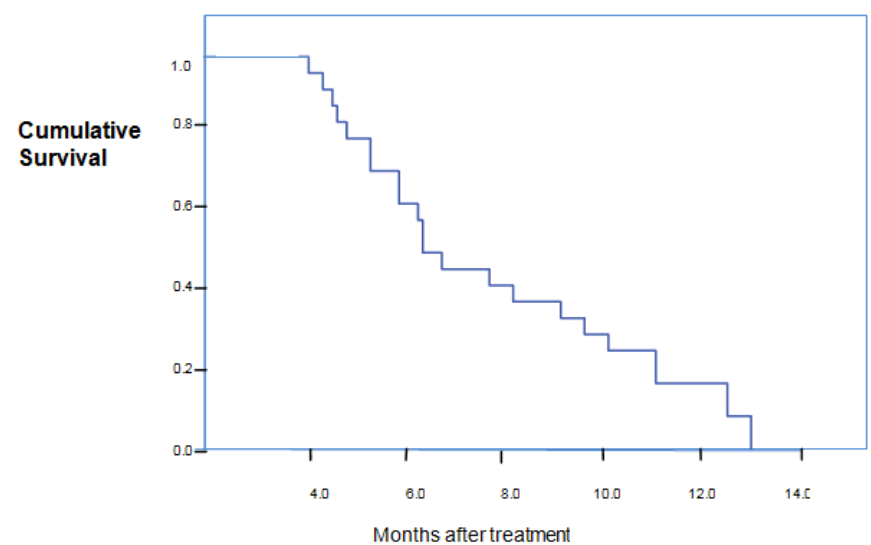

Table (2): Treatment related toxicity.

\begin{tabular}{|c|c|c|c|c|}
\hline Toxicity & $\begin{array}{l}\text { Grade } 1 \\
\text { NO } \%\end{array}$ & $\begin{array}{c}\text { Grade } 2 \text { NO } \\
\%\end{array}$ & \begin{tabular}{c}
\multicolumn{2}{c}{ Grade 3} \\
NO $\%$
\end{tabular} & $\begin{array}{c}\text { Grade } 4 \text { NO } \\
\%\end{array}$ \\
\hline Leucopenia & $4 \quad 16$ & 1040 & 936 & 28 \\
\hline Neutropenia & 28 & $10 \quad 40$ & $10 \quad 40$ & $\begin{array}{ll}3 & 12 \\
\end{array}$ \\
\hline Anemia & $\begin{array}{ll}6 & 24 \\
\end{array}$ & $5 \quad 20$ & 936 & 1 \\
\hline Thrombocytopenia & $4 \quad 16$ & $6 \quad 24$ & 1248 & 0 \\
\hline Nausea & 32 & $6 \quad 24$ & $\begin{array}{ll}3 & 12 \\
\end{array}$ & 0 \\
\hline Vomiting & 32 & 12 & 1 & $\begin{array}{ll}0 & 0 \\
\end{array}$ \\
\hline Diarrhea & 28 & $3 \quad 12$ & 0 & 0 \\
\hline Anorexia & $\begin{array}{ll}5 & 20 \\
\end{array}$ & $7 \quad 28$ & $8 \quad 32$ & $\begin{array}{ll}0 & 0 \\
\end{array}$ \\
\hline Stomatitis & 28 & 28 & 0 & 0 \\
\hline Rash & 12 & 8 & 0 & 0 \\
\hline Alopecia & $4 \quad 16$ & 4 & 0 & 0 \\
\hline Fatigue & $14 \quad 56$ & 12 & 0 & 0 \\
\hline Fever & 32 & 0 & 0 & 0 \\
\hline Peripheral neuropathy & 28 & 0 & 0 & 0 \\
\hline Total bilirubin & $4 \quad 16$ & 2 & 0 & 0 \\
\hline AST & $6 \quad 24$ & 16 & 4 & 0 \\
\hline ALT & 28 & 20 & 8 & 0 \\
\hline Creatinine & 24 & 12 & 0 & 0 \\
\hline
\end{tabular}

AST: Aspartate aminotransferase . ALT: Alanine aminotransferase. 
Table (3): Results of clinical benefit response.

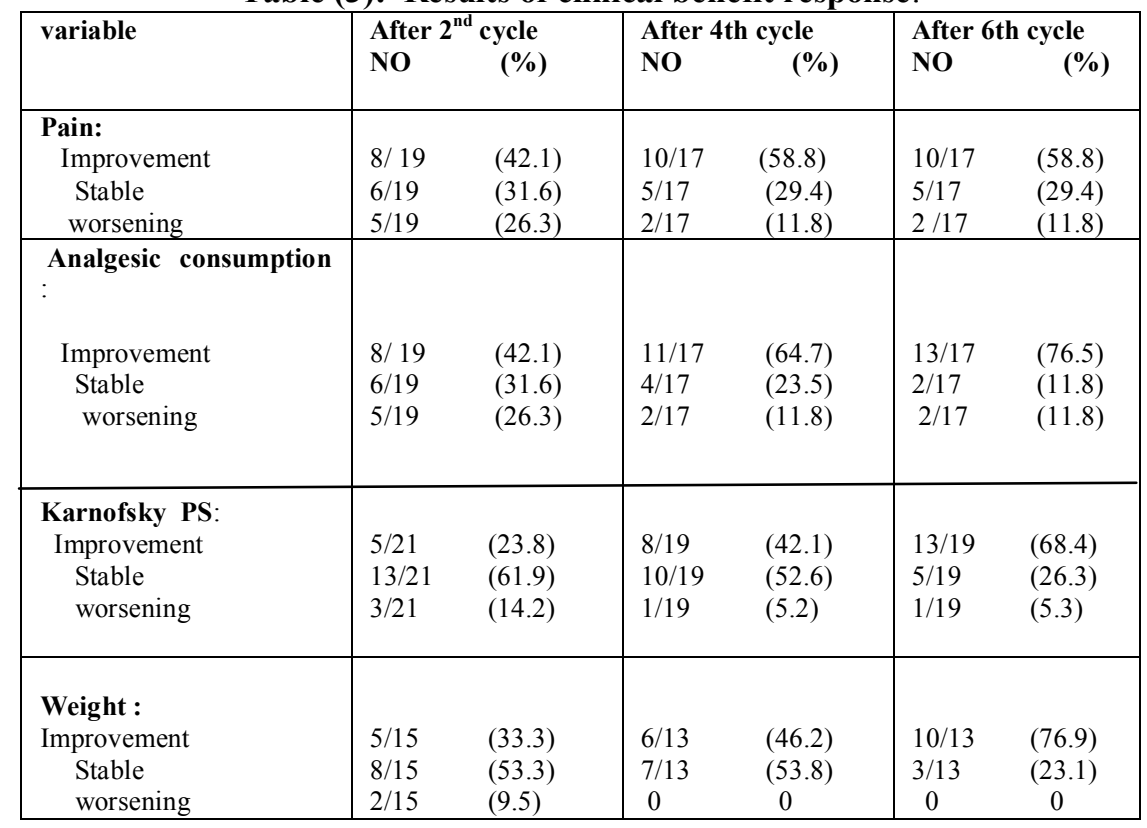

\section{Discussion:}

Pancreatic cancer is one of the most chemotherapy-resistant tumors. For many years, 5-FU was been the drug of choice in treating patients with pancreatic cancer, with objective responses ranging from $0 \%-60 \%$ in different published studies.(3)

In the mid 1990s, gemcitabine was approved for treatment of metastatic pancreatic cancer (3). The strategy to improve the treatment of advanced and metastatic pancreatic cancer since then has been focused on adding a second agent to gemcitabine. We conducted the present study to evaluate the efficacy and toxicity of gemcitabine and cisplatin combination therapy in twenty-five Egyptian patients with metastatic pancreatic cancer. According to results of our study, this combination therapy seems to be effective and well tolerated. No complete responses were documented, but partial response was achieved in $20 \%$ of patients and stable disease was observed in $64 \%$ of patients. The positive impact of the gemcitabine and cisplatin combination chemotherapy is reflected by the observed median survival of 7.1 months in our patients.

For most cancer, tumor-related symptoms are closely related to tumor bulk, in pancreatic cancer even small reductions in tumor size may result in significant clinical benefit as a result of the location of the tumor (27).In this respect, gemcitabine has been proved by many studies to be more effective than standerd 5-FU chemotherapy in treatment patients with pancreatic cancer.(28)

Partial response and stable disease in combination with clinical benefit response was reasonable treatment goal in patients with pancreatic cancer. In our study, after second cycle chemotherapy, clinical benefit response was observed in most of patients. Pain improved in $42 \%$ of patients, with $>50 \%$ reduction of analgesic consumption. Karnofsky PS improved by $>20 \%$ in $23.8 \%$ of patients, and $33.3 \%$ experienced a weight gain of $>7 \%$ from baseline.

(OS) were still disappointing. The median TTP and OS in the current study were 4.6 and 7.1 months respectively, which is comparable with the published studies of this combination, where the range of TTP was between 3.6 to 7.4 months, and the range of OS was between 5.6 to 9.6 months (17-23). But, both TTP and OS in the combination studies were better than those reported in most studies of gemcitabine monotherapy for advanced pancreatic cancer (TTP 2-3 months, overall survival about 6 months) (3-5).

The major toxicity of the gemcitabine and cisplatin combination is myelosuppression. In many studies using this combination, the incidence of grade 3-4 neutropenia and grade 3-4 thrombocytopenia were between $50 \%$ and $68 \%(17-23)$. Hematological toxicity in our study was also high, with a $52 \%$ incidence of grade $3-4$ neutropenia and a 48\% incidence of thrombocytopenia. Although the incidences of G3-4 neutropenia and thrombocytopenia in our study were high, most of such episodes were transient and resolved spontaneously, except in three patients were required hospitalization as a result of grade 4 neutropenia.

The plateau of efficacy results with gemcitabine combinations with standard cytotoxic drugs suggest that this strategy should be superseded by the study of novel therapeutic approaches in order to improve the prognosis of patients with pancreatic cancer. Recent data with the angiogenesis inhibitor bevacizumab and the EGFR-1 inhibitors cetuximab and erlotinib hold hopes that a paradigm shift in the management of advanced pancreatic cancer is forthcoming (24-26). 


\section{References}

[1] Glimelius B: Pancreatic and hepatobillary cancers: adjuvant therapy and management of inoperable disease. Ann Oncol 2000:11 (suppl 3):153-159.

[2] Parkin DM, Bray F, Ferlay I, Pisani P: Estimating the world cancer burden: Globocan 2000. Int J Cancer 2001;94:154-156

[3] Burris HA 3rd, Moore MJ, Andersen J, Green MR, Rothenberg ML, Modiano MR, et al. Improvements in survival and clinical benefit with gemcitabine as first-line therapy for patients with advanced pancreas cancer: a randomized trial. J Clin Oncol 1997; 15:2403-13.

[4] Bramhall SR, Rosemurgy A, Brown PD, et al: Marimastat as first-line therapy for patients with unresectable pancreatic cancer: a randomized trial. J Clin Oncol 2001;19:3447-3455.

[5] Bramhall SR, Schulz J, Nemunaitis J, et al: A double blind placebo controlled, randomised study comparing gemcitabine and marimastat with gemcitabine and placebo as first line therapy in patients with advanced pancreatic cancer. Br $\mathrm{J}$ Cancer 2002;87:161-167.

[6] Colucci G, Giuliani F, Gebbia V, et al: Gemcitabine alone or with cisplatin for the treatment of patients with locally advanced and/or metastatic pancreatic carcinoma: A prospective, randomized phase III study of the Gruppo Oncologico dell'Italia Meridionale. Cancer 2002;94:902-910.

[7] Heinemann V, Quietzsch D, Gieseler F, et al: A phase III trial comparing gemcitabine plus cisplatin vs. gemcitabine alone in advanced pancreatic carcinoma. Proc Am Soc Clin Oncol 2003;22:250, (abstr 1003)

[8] Rocha Lima CM, Green MR, Rotche R, et al: Irinotecan plus gemcitabine results in no survival advantage compared with gemcitabine monotherapy in patients with locally advanced or metastatic pancreatic cancer despite increased tumor response rate. $\mathrm{J}$ Clin Oncol 2004;22:1430-1438.

[9] Burris H, Storniolo AM: Assessing clinical benefit in the treatment of pancrease cancer: gemcitabine compared to 5-fluorouracil. Eur J Cancer 1997;33(suppl 1):518-522.

[10] Hochster HS, Haller DG, De Gramont A, et al: Consensus report of the international society of gastrointestinal oncology on the therapeutic progress in advanced pancreatic cancer. Cancer 2006;107:676-685.

[11] Moore MJ, Goldstein D, Hamm J, Figer A, Hecht JR, Gallinger S, et al. Erlotinib plus gemcitabine compared to gemcitabine alone in patients with advanced pancreatic cancer. A phase III trial of the National Cancer Institute of Canada Clinical Trials Group [NCIC-CTG]. Proc Am Soc Clin Oncol 2005;24:(abstr 1).

[12] Reni M, Cordio S, Milandri C, Passoni P, Bonetto E, Oliani C, et al. Gemcitabine versus cisplatin, epirubicin, fluorouracil, and gemcitabine in advanced pancreatic cancer: a randomised controlled multicentre phase III trial. Lancet Oncol 2005;6:369-76.

[13] Heineman V, Hinke A, Boch S, Louvet C: Meta-analysis of randomized trials: evaluation of benefit of chemotherapy from combination chemotherapy applied in advanced pancreatic cancer. Ann Oncol 2006;17(suppl 9):226.

[14] Milella M, Carlini P, Gelibter A, et al: Does a second drug added to gemcitabine (G) improve outcome over G in advanced pancreatic cancer? A pooled analysis of 5561 patients enrolled in 16 phase III trials. Ann Oncol 2006;17(suppl 9)226-227.

[15] Therasse P, Arbuck SG, Eisenhauer EA, et al: New guidelines to evaluate the response to treatment in solid tumors. J Natl Cancer Inst 2000; $92: 205-216$.

[16] National Cancer Institute: Common Toxicity Criteria Manual, version 2.0, June 1, 1999.http:/ ctep.cancer.gov/reporti / ctc. html

[17] Brodowicz T, Wolfram RM, Kostler WJ, Tomek S, Vaclavik I, Steger GG, et al. Phase II study of gemcitabine in combination with cisplatin in patients with locally advanced and/or metastatic pancreatic cancer. Anticancer Drugs 2000;11:623-8.

[18] Clayton AJ, Mansoor AW, Jones ET, Hawkins RE, Saunders MP, Swindell R, et al. A phase II study of weekly cisplatin and gemcitabine in patients with advanced pancreatic cancer: is this a strategy still worth pursuing? Pancreas 2006;32:51-7.

[19] Heinemann V, Wilke H, Mergenthaler HG, Clemens M, Konig H, Illiger HJ, et al. Gemcitabine and cisplatin in the treatment of advanced or metastatic pancreatic cancer. Ann Oncol 2000;11:1399-403.

[20] Philip PA, Zalupski MM, Vaitkevicius VK, Arlauskas P, Chaplen R, Heilbrun LK, et al. Phase II study of gemcitabine and cisplatin in the treatment of patients with advanced pancreatic carcinoma. Cancer 2001;92:569-77.

[21] Cascinu S, Labianca R, Catalano V, Barni S, Ferrau F, Beretta GD, et al. Weekly gemcitabine and cisplatin chemotherapy: a welltolerated but ineffective chemotherapeutic regimen in advanced pancreatic cancer patients. A report from the Italian Group for the Study of Digestive Tract Cancer (GISCAD). Ann Oncol 2003;14:205-8.

[22] Ko AH, Dito E, Schillinger B, Venook AP, Bergsland EK, Tempero MA. Phase II study of fixed dose rate gemcitabine with cisplatin for metastatic adenocarcinoma of the pancreas. J Clin Oncol 2006;24:379-85.

[23] Ueno H, Okusaka T, Ikeda M, Chigusa Morizane C, et al: Phase II Study of Combination Chemotherapy with Gemcitabine and Cisplatin for Patients with Metastatic Pancreatic Cancer. Jpn J Clin Oncol 2007.

[24] Kindler HL, Friberg G, Stadler WM, et al: Bevacizumab (B) plus gemcitabine (G) in patients with advanced pancreatic cancer: Updated results of a multi-center trial. J Clin Oncol 22:315s, 2004 (suppl 14; abstr 4009)

[25] Xiong HQ, Rosenberg A, LoBuglio A, et al: Cetuximab, a monoclonal antibody targeting the epidermal growth factor receptor, in combination with gemcitabine for advanced pancreatic cancer: A multicenter phase II trial. J Clin Oncol 22:2610-2616, 2004

[26] Moore MJ, Goldstein D, Hamm J, et al: Erlotinib improves survival when added to gemcitabine in patients with advanced pancreatic cancer: A phase III trial of the National Cancer Institute of Canada Clinical Trial Group (NCIC-CTG). Proc 2005 Gastrointestinal Cancers Symposium, Orlando, FL, January 27-29, 2005 (abstr 77).

[27] Carmichael J, Fink U, Russl RCG et al: Phase II study of gemcitabine in patients with advanced pancreatic cancer. Br J Cancer 1996; 73: 101-105.

[28] Heinemann V: Gemcitabine - based combination treatment of pancreatic cancer. Semin Oncol 2002;29: 25-35. 